\title{
Collagen Type IV Measurement
}

National Cancer Institute

\section{Source}

National Cancer Institute. Collagen Type IV Measurement. NCI Thesaurus. Code C103383.

The determination of the amount of the collagen type IV in a sample. 